\title{
Self-Esteem, Social Maturity and Well-Being Among Adolescents With And Without Siblings
}

\author{
${ }^{1}$ Prof. Nazirul Hasnain and Ms. ${ }^{2}$ Parul Adlakha \\ Depatment of Psychology Jamia MIllia Islamia, New Delhi, India
}

\begin{abstract}
The present study was designed to investigate the differences in the levels of self-esteem social maturity and well-being between adolescents with and without siblings. It also investigated the percentage of variance counted by social maturity and self-esteem in the well-being of adolescents with and without siblings. For this purpose a total sample of 100 students studying in $10^{\text {th }}$ to $12^{\text {th }}$ grades was taken on purposive basis from the schools of Delhi and National Capital Region (NCR) of India. In order to collect the data Self-esteem Inventory by Coopersmith, Social Maturity scale by Rao and PGI Well-being measure by Verma \& Verma were administered on the participants. Non-significant differences were obtained between adolescents with and without siblings on self-esteem and well-being. However, significant difference was found between adolescents with and without siblings on social maturity showing that adolescents without siblings had higher mean social maturity score than adolescents with siblings. The results of regression analysis showed significant contribution of social maturity and self-esteem together in well-being of adolescents without siblings, but independently they did not contribute significantly to their well-being. The total contributions of self-esteem and social maturity in the well-being of adolescents without siblings was $13 \%$. However, in the case of adolescents with siblings social maturity and self-esteem neither together nor independently contributed significantly to their well-being.

Keywords: Adolescent with and without siblings, Self-esteem, Social maturity, Well-being.
\end{abstract}

\section{Introduction}

Self-esteem is a widely used concept both in popular language and in psychology. It refers to an individual's sense of his or her value or worth, or the extent to which a person values, approves, appreciates, prizes, or likes himself or herself (Blascovich \& Tomaka,1991).The most broad and frequently cited definition of self-esteem is Rosenberg's (1989), who described it as a favourable or unfavourable attitude toward the self. The identification of one's self or the attainment of a self-concept begins early in life and is surely one of the most important concept that an individual ever forms (Lowe, 1965). Basic Behavioural Science Task Force of the National Advisory Mental Health Council (2004) offers a fuller explanation, "self-esteem begins to develop early in life and has been studied in children as young as seven years of age. As children learn to describe aspects of themselves, such as their physical attributes, abilities and preferences, they also begin to evaluate them."

Social maturity is a term commonly used in two ways, with reference to the behavior that conforms to the standards and expectations of the adults and secondly, with reference to the behavior that is appropriate to the age of the individual under observation. Thus, the social maturation permits more detailed perception of the social environment which helps adolescents to influence the social circumstances and develop stable patterns of social behaviour (Bretsch, 1952).

Social Maturity is a personal commitment each individual must make as the attitude that will influence his/her daily lives. Individuals can opt for the socially immature attitude of self centeredness or they can opt for the socially mature attitude of genuine concern for the total well being of each other. The very informal atmosphere of self help groups where the individuals discuss and share their problems and their achievements with each other within the framework of caring and sharing without the fear of being exploited (Dilts, 1982).

Ryff (1998) proposes that some factors of well-being in particular self-acceptance, environmental mastery, and purpose in life are highly correlated with self-esteem. According to Major, Cooper, Richards and Zubek (1998) self-esteem may be thought of as a core resource that contributes to resilient personality, and a person with a resilient personality has a positive view of him or her, a sense of control and an optimistic outlook on the future. Levi (1987) defined well-being as a dynamic state of mind characterized by a reasonable amount of harmony between an individual's abilities, needs, expectations and environmental demands.

'Subjective well-being' refers to people's evaluations of their lives including cognitive judgements, such as life satisfaction and effective evaluations of moods and emotions, such as positive and negative emotional feelings. Subjective well-being is a broad concept that includes experiencing pleasant emotions, low levels of negative mood and high life satisfaction (Diener and Diener, 2009).

The above paragraphs indicate that self-esteem, social maturity and well-being as positive variables seem to have close relationship with each other. All of them to a great extent are dependent on the socio- 
Self-Esteem, Social Maturity And Well-Being Among Adolescents With And Without Siblings

psychological factors learned and developed by the individuals within the social matrix of family, society, school and other social circumstances. Seeing in this perspective it is discernible to infer that siblings providing the basic context for social learning will work as synergy for the development of self-esteem, social maturity and well-being in adolescents. Keeping this end in view the present study was undertaken to compare the selfesteem, social maturity and well-being of adolescents with and without siblings. Efforts were also made to ascertain the percentage of variance of self-esteem and social maturity in well-being of two kinds of adolescents.

\section{Previous Researches}

Adolescents who perceive their sibling relationships more positively tend to have higher self-esteem, which, in turn, is associated with less loneliness, less depression, and fewer delinquent behaviours and less substance use. Moreover, there exists a bidirectional relationship between adolescent self-esteem and the quality of their sibling relationships, suggesting that a more positive sibling relationship helps to enhance adolescent self-esteem, and that higher adolescent self-esteem predicts a more positive sibling relationship (Yeh \& Lempers, 2004). Relationships with siblings provide a context for life experiences. Siblings play a major role during the transition to adulthood, in social relationships of children and in the overall development across the life course (Conger and Kramer, 2010). Social support received from siblings relate to psychological adjustment in emerging adulthood. Sibling support partially compensates for low support from friends for all of the wellbeing measures and completely compensates for self-esteem, depression, and life satisfaction ( Milevsky, 2005). Patil (2003) reports that adolescence is accompanied by some stress related to school, family and peers, and this stress can at times be difficult to manage. Also, certain kinds of developmental problems arise especially problems that have to do with self perceptions, feelings about who we are and negative emotions in general. Thus, adolescents who have significant emotional stress, their self-esteem is lowered, straining personal relationships.

Further, in their research, Pastey and Aminbhavi (2006) found that having more number of siblings influences positively the self-confidence of adolescents when compared to those having less number of siblings, however the birth order of adolescents has no significant impact on self-confidence.

Zajonc \& Marcus (1975), Claudy, Farrel, \& Dayton, (1979) found that only children appear consistently brighter, they score slightly higher on intelligence tests and do better in school. The study also found only children to be more mature, more sensitive socially. The assumption that having a sibling provides practice with skills that generalize to peer relations was studied by Lockwood, Gaylord, Kitzmann and Cohen (2002). The results suggested that only children were similar to classmates in terms of number of close friendships and friendship quality. Falbo and Polit(1986) found that only children score much more than children with siblings, when examined on the dimension of psychological adjustment

Glenn and Hoppe (1984) conducted a study to estimate the effects of number of siblings on eight dimensions of psychological well-being among children. The evidence from the study showed that the popular stereotype of the unhappy, maladjusted only child were not true. Conger (1997) carried a study on parents, siblings, psychological control and adolescents. Results of the study indicated that psychological control both by parents and by siblings contributes to increase adolescents adjustment problems and to diminished selfconfidence.

In addition, Singh, Malik \& Reema (2007) found that social support plays an important role in maintaining the health and well-being as it gives the adolescents a feeling of being loved, cared for, esteemed valued and belonging. Supporting relationships like close friends or siblings contribute to an individual's sense of security, positive evaluations of life experiences, personal worth and competence and in turn enhances wellbeing.

The above studies reveal that to be alone or to be with siblings brings many psychological consequences. Keeping this end in view, the present study was conducted to explore the difference between selfesteem, social maturity and well-being of only adolescents and adolescents with siblings and also to explore the contribution of self- esteem and social maturity in their well-being. This is important to note that adolescence is a crucial stage of development where various psycho-physical and social developments almost become stabilized. Hence, measuring and comparing the adolescents with and without siblings with their specific characteristics on the above variable will be important.

\section{Hypotheses}

There were 5 hypotheses formulated to explore the differences between social maturity, well-being and self-esteem of adolescents with and without siblings and the contribution of self-esteem and social maturity in the well-being of adolescents with and without siblings. Specifically, the following hypotheses were formed for testing by the findings of the study:

1. There will be significant difference between Self-Esteem of adolescents with and without siblings

2. There will be significant difference between Social Maturity of adolescents with and without siblings. 
3. There will be significant difference between Well-Being of adolescents with and without siblings.

4. There will be significant contributions of Self-Esteem and Social Maturity together and independently in the well-being of adolescents with siblings.

5. There will be significant contributions of Self-Esteem and Social Maturity together and independently in the well-being of adolescents without siblings.

\section{Research Methodology}

The present study includes a simple two group design, with one group of adolescents who had siblings and the other group did not have siblings.

\subsection{Sample}

Participants of the present study were taken on a purposive basis from schools in Delhi and NCR( Delhi, India). A total of 100 students were taken in the study, among them there were 50 adolescents with siblings and 50 adolescents without siblings, their age ranged from 15 to 18 years. They were studying in Secondary and Senior Secondary schools. Students who did not have any siblings and students who had one or two siblings were taken on the basis of questions asked in the classroom.

\subsection{Procedure}

Permission was taken from the Principal of these schools to administer the tests on the students. He/she referred the classes. Scales of social maturity, well-being and self-esteem were administered on them and total score for each scale was found out for all participants.

\subsection{Instrumentations}

Rao's Social Maturity Scale (RSMS) (Rao,1998) was used to measure the Social Maturity of the subjects under study. The scale measures Social Maturity along three dimensions: Personal Adequacy (includes components like work orientation, self-direction and ability to take stress), interpersonal adequacy (includes components like communication, enlightened trust, and cooperation), and social adequacy (includes components like social commitment, social tolerance, and openness to change).

The scale consists of 90 items along 9 sub-scales. RSMS is a four-point scale and the subject has to give the responses to the statements by encircling one of the 4 suitable responses-Strongly Agree(SA), Agree(A), Disagree(D), and Strongly Disagree(SD). The social maturity scale can be administered to the respondents in groups in the regular class-room situation. The instructions provided on the test booklet are selfexplanatory. Scoring of the social maturity scale requires score of each item to be entered in the scoring blank. The Scoring stencil is placed on the scoring blank and the scores for each of the three sub-scales under the three dimensions of social maturity scale are obtained by moving the stencil on the scoring blank and viewing the same number through the stencil holes. When No.1 is visible through the punched holes, it gives the score of the first three sub-scales of the first dimension. Similarly Nos. 2 and 3 provide scores for the sub-scales of the second and third dimensions respectively. However, in the present investigation total scores of the participants by totalling the scores on individual dimensions were obtained. Higher score represents the better mature response, Maximum score being 360 and Minimum mature score 90. Reliability coefficient obtained between the scores on Hindi and English versions was 0.98. The scale seems to be more sensitive to the presence of a trait than to its absence or lack of it, evident from the significantly higher mean values of the groups rated mature, and the absence of the mean difference between the groups rated moderately mature and immature. On the basis of these observations and findings, the validity of the tool is acceptable.

PGI General Well-Being Measure by Verma and Verma(1989) was used to measure the Well-Being of the subjects under study. The test consists of 20 items and the subject has to tick mark the statement that he/she feels is appropriate and applies to him/her. The PGI Well-being measure is scored by counting the number of ticks which constitutes the total well-being score of a subject. Reliability by Kuder Richardson formula was found to be 0.98 while Test-Retest Reliability was 0.91 for the English version. The scale showed significant relation with another well-being sale, with Quality of Life, and to some extent with learned helplessness.

The Coopersmith Self-Esteem Inventory (SEI) by Coopersmith(1981) was used to measure the selfesteem of the subjects under study. The SEI is designed to measure the evaluative attitudes towards the self in social, academic, family and personal area of experience. The short-form of the scale consists of 25 items. In the present study short-term of the scale was used. The subject has to put an " $\mathrm{X}$ " in the column of either "like me", if he/she thinks that the item signifies what he feels or "unlike me", if he/she thinks that the item does not signify what he feels. Reliability coefficients ranging from 0.71 to 0.80 have been reported when alternate forms were used. The Concurrent and Predictive Validity of the SEI is good. SEI scores are significantly correlated to creativity, academic achievement, perceived popularity and family adjustment. High SEI scores are 
accompanied by high personality adjustment scores. SEI scores are also correlated with scores on achievement and intelligence.

\subsection{Hypotheses Testing}

In order to test the hypotheses t- test and step-wise regression analysis were applied.

\section{Figures and Tables}

Table No.1: Comparison of mean self- esteem, social maturity and well-being of adolescents with and without siblings.

\begin{tabular}{|c|c|c|c|c|c|}
\hline Variables & Comparisons & Mean & S.D. & $\mathrm{t}$ & Significance \\
\hline \multirow{2}{*}{ Self-esteem } & With sibling & 59.6 & 17.5 & \multirow{2}{*}{0.96} & \multirow{2}{*}{$>0.05$} \\
\hline & Without siblings & 62.9 & 16.4 & & \\
\hline \multirow{2}{*}{ Social maturity } & With sibling & 234.52 & 18.5 & \multirow{2}{*}{2.49} & \multirow{2}{*}{$<0.01$} \\
\hline & Without siblings & 243.78 & 18.6 & & \\
\hline \multirow{2}{*}{ Well-being } & With sibling & 11.3 & 4.13 & \multirow{2}{*}{0.57} & \multirow{2}{*}{$>0.05$} \\
\hline & Without siblings & 10.8 & 4.55 & & \\
\hline
\end{tabular}

A look at the above table depicts that the means of self-esteem scores of adolescents with siblings and without siblings were 59.6 and 62.9, and their SDs were 17.5 and 16.4 respectively. $t$ between the means was 0.96 , which was not significant at .05 level of significance. Thus, hypothesis 1 was not confirmed.

Table 1 depicts that the means of social maturity scores of adolescents with siblings and without siblings were 234.52 and 243.78, and their SDs were 18.5 and 18.6 respectively. t- ratio between the means was 2.49 , which was significant at .01 level of significance. Thus, hypothesis 2 was confirmed.

The above table also depicts that the means of well-being scores of adolescents with sibling and without siblings were 11.3 and 10.8, and their SDs were 4.13 and 4.55 respectively. $t$ - ratio between the means was 0.57 , which was not significant at .05 level of significance. Hence, hypothesis 3 was not confirmed.

Multiple Regression Analysis was carried out to find out the contribution of self-esteem and social maturity in the well-being of adolescents with and without siblings.

Separate Analysis were carried out for adolescents with siblings and without siblings.

Table No. 2: Results of Multiple Regression Analysis for well-being as a criterion variable and self-esteem and social maturity as predictors together of adolescents with siblings.

\begin{tabular}{|c|c|c|c|c|c|}
\hline $\mathrm{R}$ & $\mathrm{R} 2$ & $\begin{array}{c}\text { ADJUSTED } \\
\mathrm{R} 2\end{array}$ & Standard Error & F value & $\begin{array}{c}\text { Significance } \\
\text { Level }\end{array}$ \\
\hline 0.21 & 0.45 & 0.004 & 4.12 & 1.107 & $>0.05$ \\
\hline
\end{tabular}

The above table shows the results of regression analysis in case of adolescents with siblings. In the table, $\mathrm{R}$ is $0.21, \mathrm{R} 2$ is 0.45 and Adjusted $\mathrm{R}$ is 0.004 , which indicate that when self-esteem and social maturity were taken as predictors, the contribution of the two variables together in well-being in case of adolescents with siblings came to be 0.004 , which was, not significant. Since the F- ratio was not significant at any significance level further analysis was not required. Thus, hypothesis 4 was not confirmed.

Table No. 3: Results of Multiple Regression Analysis for well-being as a criterion variable and self-esteem and social maturity as predictors together of adolescents without sibling.

\begin{tabular}{|c|c|c|c|c|c|}
\hline $\mathrm{R}$ & $\mathrm{R} 2$ & $\begin{array}{c}\text { ADJUSTED } \\
\mathrm{R} 2\end{array}$ & Standard Error & F value & $\begin{array}{c}\text { Significance } \\
\text { Level }\end{array}$ \\
\hline 0.41 & 0.17 & 0.136 & 4.23 & 4.85 & $<0.01$ \\
\hline
\end{tabular}

Table 3 depicts the results of regression analysis in case of adolescents without siblings. In the above table, $\mathrm{R}$ was $0.41, \mathrm{R} 2$ is 0.17 and Adjusted $\mathrm{R}$ is 0.136 , which indicate that when self-esteem and social maturity were taken as predictors, the contribution of the two variables together in well-being in case of adolescents without sibling came to be 0.136 , and F-ratio was significant at 0.01 level of significance. It means that social maturity and self-esteem together contribute $13 \%$ variance to the well-being of adolescents without siblings. Hence, first part of hypothesis 5 was confirmed. 
Self-Esteem, Social Maturity And Well-Being Among Adolescents With And Without Siblings

Table No. 4: Results of regression analysis for well-being as a criterion, and self-esteem and social maturity as independent predictors of adolescents with siblings.

\begin{tabular}{|l|c|c|c|}
\hline \multicolumn{1}{|c|}{ Variables } & $\begin{array}{c}\text { Standardised } \\
\text { Beta Value }\end{array}$ & $\mathrm{t}$ & Significance \\
\hline Self-Esteem & 0.113 & 0.75 & $>0.05$ \\
\hline Social Maturity & 0.214 & 1.44 & $>0.05$ \\
\hline
\end{tabular}

Table 4 shows that Standardised Beta values for self-esteem social maturity and were 0.113 and 0.214 and $t$ were 0.75 and 1.44 respectively which were not significant at 0.05 level. It means that self-esteem and social maturity did not contribute independently to the well-being of adolescents with siblings. Thus, the second part of hypothesis 5 was not confirmed.

\section{Discussion}

Table 1 shows that t-ratio for self-esteem was found to be non-significant at 0.05 level. Findings of the present study show that adolescents with and without siblings had almost equal self-esteem. The results of the study conducted by Lockwood et.al (2002) suggest that the only children were similar to classmates in terms of number of close friendship and friendship quality. Thus, though siblings play a role during the transition to adulthood, in social relationships of children and in the overall development across the life course (Conger and Cramer, 2010), but it all depends on a more positive sibling relationship (Yeh and Lempers, 2004). Yeh and Lempers (2004) also found that sibling relationship predicts a more positive self-esteem. They found bidirectional relationship between adolescent self-esteem and the quality of their sibling relationships, suggesting that a more positive sibling relationship helps to enhance adolescent self-esteem. It indicates that sibling contribution to self-esteem is not so strong as the contribution of parents. The finding of the present study is not in consonance with the findings of Steiner (1984), that children with siblings possessed the highest level of self-esteem. It is also in negation of the findings of Yeh and Lempers (2004).

The same table reveals that $\mathrm{t}$ value for social maturity was found to be significant at 0.01 level, where social maturity score of adolescents without siblings was significantly greater than that of adolescents with siblings. It means that adolescents without siblings had better social maturity than adolescents with siblings.

Researches show that single children have more confidence and better self concept than children with siblings. Being more confident they fetch more opportunities of interaction with teachers and participation in cocurricular activities which consequently enhances their social skills. Research conducted by Zajonc \& Marcus (1975) and Claudy, Farrel, \& Dayton (1979) showed that only children appear consistently brighter, they score slightly higher on intelligence tests and do better in school. It was also found that only children were more mature, more sensitive socially, more fastidious and more cultured. The findings of the present study are in line with the results of these studies. Research conducted by Falbo and Polit (1986) examined the psychological adjustment of only children, typically these studies indicated that only children scored much like children with siblings. They reported that many only children received services at psychological clinics; however, this type of finding should not be construed to mean that only children are more likely to be maladjusted. The findings of the present study did not indicate such a condition.

Lockwood, Gaylord, Kitzmann and Cohen (2002) found that only children were similar to classmates in terms of number of close friendships and friendship quality. Riggio (1999) found differences in personality and social skills of 146 adults with one or more siblings and 51 adults without siblings and found only a marginal difference between individuals with and without siblings in neuroticism, and no differences in various social skills or overall social competence. Thus the findings of the present study is not in consonance with results of these studies. Also, Table 1 reveals that $t$ score for well-being was found to be non- significant at 0.05 level. It seems that though the only children often have to face the burden of responsibilities and expectations of the parents and assume adult roles early in their lives as they do not have siblings to share these responsibilities with but becoming more socially mature help to maintain their well-being. Instead of looking up to siblings for support such children look up to the parents, but many times the parents are not able to respond in ways that the child expects them to or the way he wants them to, even then greater opportunities of learning the social skills seem to make them face these difficult situations with appropriate strength, keeping their well-being intact. In the case of adolescents who have siblings the emotional support they receive from the siblings in times of distress and crisis may lead to maintenance and enhancement in their well-being. Thus in case of adolescents without siblings support from parents, social skill and maturity help them to maintain and enhance their wellbeing and in case of adolescents with siblings same is done by siblings and parents exhibiting no difference between the well-being of adolescents with and without siblings.

However, studies conducted by researchers confirm the role of siblings in the well-being of children. According to research conducted by Yuan (2009) sibling structure (the number of siblings, full versus step or half-siblings, the relative age of siblings, and the gender composition of siblings) influences adolescents' mental 
Self-Esteem, Social Maturity And Well-Being Among Adolescents With And Without Siblings

health and the relationship quality mediates or interacts with sibling structure. Results indicated that sibling structure moderates the association between sibling relationship quality and adolescents' mental health. Thus, sibling structure and relationship quality appear to be interconnected in their influence on adolescents' mental health. The assumption that having a sibling provides skills that help to manage conflict in stressful situations was studied by Lockwood, Gaylord, Kitzmann \& Cohen (2002). The results indicated that only children were more aggressive, suggesting that having a sibling may be especially helpful for learning to manage conflict. The findings of the present study negate these findings.

Results of regression analysis of adolescents with siblings revealed that self-esteem and social maturity did not show significant contribution jointly in the well-being. Table 2 shows that social maturity and selfesteem together contribute negligible variance to well-being of adolescents with siblings. It means that selfesteem, social maturity and well-being function independently in so far as the adolescents with siblings are concerned.

Results of regression analysis of adolescents without siblings revealed that self-esteem and social maturity jointly show significant contribution in the well-being of adolescents. Table 3 shows that social maturity and self-esteem together contribute $13.6 \%$ variance to well-being of adolescents without siblings. However, the variance counted by social maturity is slightly higher $(21.4 \%)$ than the variance counted by selfesteem (11.3\%). Table 4 shows that the t-score for social maturity was 1.44 while that for self-esteem was 0.75 both were non-significant at 0.05 level of significance. It means that social maturity and self-esteem together contribute to the well-being of adolescents without siblings with social maturity playing a slightly better role than self-esteem. Thus, well-being of adolescents without sibling seem to stem from stronger self-esteem and better social maturity, but in case of adolescents with siblings, well-being works independently as powerful strength.

\section{Conclusion}

Every study suffers some limitations because of the limited time and resources at hand of the researcher. Despite sincere efforts on the part of the researcher there were certain drawbacks and limitations in the present study. Some of the limitations were:

- The sample size of the study was relatively small and thus the research cannot be generalised easily.

- The study was conducted on adolescents studying only in secondary and senior secondary school, which further reduces the scope of generalisation.

- The variables treated as independent variable was not exhaustive. Various demographic variables such as gender, family, socio-economic factors could have been included for a clearer picture of variable section.

- $\quad$ The samples could have been selected from more schools in the Delhi-NCR region.

Despite these limitations the present study was planned and carried out with utmost care by using scales that capture reliably and validly the aspects of self-esteem, social maturity and well-being.

The implications of the present study very clearly suggest that though siblings play important roles in the life of adolescents but it does not have strong lining with the variables investigated in the present study. Rather, roles played by parents in making the adolescents more socially mature is evident. Likewise, well-being of adolescents with siblings seems to be independent of self-esteem and social maturity. They themselves play roles in their life. However, adolescents without siblings seem to get strength for well-being from a better social maturity. The findings of the present study presents a positive picture of only child as against the stereotype of inferior only child.

\section{References}

[1]. Blascovich, J. \& Tomaka, J. (1991).Measures of Self-Esteem. Journal of Personality and Social Psychology, 65, 248-260

[2]. Rosenberg, M. (1989). Dialectic balance in the polar model of self. Ethos, 17, 88-113.

[3]. Lowe (1965). Effective correlates of transformational and transactional leadership: A meta analytic review. Leadership Ouarterly,7, 385-426 Basic Behavioural Science Task Force of the National advisory Mental Health Council (2004). Basic Behavioural Science Research for Mental Health: Socio-cultural and Environmental Practices. American Psychologist, 51,722-731.

[4]. Bretsch, H.S., 1952, social skills and activities of socially accepted and unaccepted adolescents. Journal of Education Psychology, 443- 449.

[5]. Dilts, R. (1982). www.magamc.ca/Social_Maturity.htm. Retrieved on 12th May 2011

[6]. Ryff, D. (1998). The contours of positive human health. Psychological Inquiry, 1-28.

[7]. Major,B., Cooper,M., Richards \& Zubek,T.(1998).Personal appraisals and coping. Journal of Personality and Social Psychology,74, 735-757.

[8]. Levi, I. (1987). Fitting work to human capacities and needs: Improvements in the contents and organisation of work. In Kalino et al., Psychological factors at work. Geneva: World Health Organisation Diener \& Diener(2009).The well-being: The collected works of Diener. Social Indicators Research series 37, London: Springer Dordrecht Hiedelberg.

[9]. Yeh, H.\& Lempers, J.(2004).Perceived Sibling Relationships and Adolescent Development. Journal of Youth and Adolescence, $33,133-147$. 
[10]. Conger, K. \& Kramer, L. (2010). Sibling Relationships During the Transition to Adulthood. Child Development Perspectives, 4, 69,71 .

[11]. Milevsky, A.(2005).Compensatory patterns of sibling support in emerging adulthood: Variations in loneliness, self-esteem, depression and life satisfaction. Journal of Social and Personal Relationships, 22, 743-755.

[12]. Patil, M. (2003). Family Matters, Vijaya Times, Page 3, Saturday, 6 September, 2003.

[13]. Pastey, G. \& Aminbhavi, A. (2006). Impact of Emotional Maturity on Stress and Self-confidence of Adolescents. Journal of the Indian Academy of Applied Psychology, 32, 66-70.

[14]. Zajonc, R. B. \& Marcus, G. B. (1975). Birth order and intellectual development. Psychological Review, 82, 74-88.

[15]. Claudy G, Farrel, U. S. \& Dayton, C. W. (1979). The consequences of being an only child.

[16]. Palo Alto, CA: American Institute for Research.

[17]. Lockwood, R.; Gaylord, N.K.; Kitzmann, K. \& Cohen R. (2002). Are Only Children Missing Out? Comparison of the Peer-Related Social Competence of Only Children and Siblings. Journal of Social and Personal Relationships, 19, 299-316.

[18]. Falbo,T. \&. Polit, D. (1986).Quantitative Review of the Only Child Literature: Research Evidence and Theory Development. Psychological Bulletin, 100, 176-189.

[19]. Glenn, N. \& Hoppe, S. (1984) Only Children as Adults: Psychological Well-Being. Journal of Family Issues, 5, $363-382$.

[20]. Conger, K. (1997). Parents, siblings, psychological control and adolescent adjustment. Journal of Adolescent Research, 12, 113138.

[21]. Singh, S., Malik, M. \& Reema (2007). Role of psychosocial contributors on pathways to well-being. Journal of Indian Health Psychology, 1, 197-204.

[22]. Rao, N. (1986). Manual for Rao's Social Maturity Scale. Agra : National Psychological Corporation.

[23]. Verma, S. \& Verma, A. (1989). PGI General Well-Being Measure Manual. Lucknow: Ankur Psychological Agency

[24]. Steiner, K. (1984) The Only Child. Illinois: ERIC publications.

[25]. Coopersmith, S. (1981). Coopersmith Self-Esteem Inventory Manual. Paolo Alto, CA: Consulting Psychologists Press

[26]. Riggio, H.R. (1999). Personality and Social Skill Differences Between Adults With and Without Siblings. Journal of Psychology, $133,514-522$.

[27]. Yuan, V. (2009). Sibling Relationships and Adolescents' Mental Health. Journal of Family Issues, 30, 1221-1244. 